\title{
Thermal Decomposition Behavior and Kinetic Study of Jamadoba Coal and Its Density Separated Macerals: A Non-Isothermal Approach
}

\author{
Deepak Chandra Sau', Amit Banerjee ${ }^{1}$, Sanchita Chakravarty ${ }^{1}$, Pragyan Senapati2 $^{*}$, \\ Rabiranjan Murmu3 ${ }^{3}$, Harekrushna Sutar ${ }^{3}$ \\ ${ }^{1}$ CSIR-National Metallurgical Laboratory, Jamshedpur, India \\ ${ }^{2}$ Mechanical Engineering Department, ITER, SOA Deemed to Be University, Bhubaneswar, India \\ ${ }^{3}$ Chemical Engineering Department, Indira Gandhi Institute of Technology, Sarang, India \\ Email: * pragyansenapati@soa.ac.in
}

How to cite this paper: Sau, D.C., Banerjee, A., Chakravarty, S., Senapati, P., Murmu, R. and Sutar, H. (2021) Thermal Decomposition Behavior and Kinetic Study of Jamadoba Coal and Its Density Separated Macerals: A Non-Isothermal Approach. $A d$ vances in Chemical Engineering and Science, 11, 203-227.

https://doi.org/10.4236/aces.2021.113013

Received: April 6, 2021

Accepted: May 29, 2021

Published: June 1, 2021

Copyright $\odot 2021$ by author(s) and Scientific Research Publishing Inc. This work is licensed under the Creative Commons Attribution International License (CC BY 4.0).

http://creativecommons.org/licenses/by/4.0/

\section{(c) (i) Open Access}

\begin{abstract}
This kinetic study focuses on determining the thermal gravimetric profile of a particular grade of Indian sub-bituminous coal. A thermogravimetric analyzer (TGA-1000) was employed to investigate the thermal behavior and extract the kinetic parameters of Jamadoba coal and its corresponding density separated macerals. The weight loss was measured in air atmosphere. The coal samples used in this study were obtained from Jamadoba mines, Jharkhand. Samples of $35 \mathrm{mg}$ and $200 \mu \mathrm{m}$ mean size were subjected to synthetic air atmospheres $\left(21 \% \mathrm{O}_{2}\right)$. Heating rates of 2,5 and $7{ }^{\circ} \mathrm{C} / \mathrm{min}$ were applied until the temperature reached $1400^{\circ} \mathrm{C}$, which was kept constant until burnout. Low heating rate was preferred so that devolatilization occurs prior to ignition and combustion. Derivative thermogravimetry (DTG) analysis method was applied to measure the weight changes and rates of weight loss used for calculating the kinetic parameters. The activation energy $\left(E_{a}\right)$ and pre-exponential factor were obtained from model-free methods by applying non-isothermal thermogravimetry analysis.
\end{abstract}

\section{Keywords}

Thermal Decomposition, Kinetic Study, Jamadoba Coal, Non-Isothermal

\section{Introduction}

India is one of the fastest-growing economies in the world. With rapid industria- 
lization and the growing demands for power supply, the energy needs are fast increasing. Coal, being a major energy source in India, meets about $52 \%$ of the primary commercial energy and generates about $66 \%$ of the total electricity [1]. It becomes important to study the thermal behavior of coal and determine the kinetic parameters of the decomposition stage. The design of coal combustion process requires the know-how of the various stages of thermal degradation in order to deduce optimum operating conditions. This greater significance on more effective utilization of coal combined with its chemical complexity raises the need for a thermogravimetry study coupled with microscopy analysis. TGA is often employed to investigate the kinetics of the decomposition process of oxidized coal so as to design the reactor and optimize the process conditions. Under this process, the mass loss rate of coal sample is observed with temperature changes in a controlled atmosphere. The mass loss computed with respect to temperature or time is shown as a thermogravimetric (TG) curve. The rate of mass loss computed with respect to temperature or time is shown as a differential thermogravimetric (DTG) curve. Applying kinetic models to the in situ degradation reaction helps in determining the kinetics of the thermal behavior of coal. The main advantages of thermogravimetry method for the study of coal combustion are credibility to ensure equal weightage to examination over the whole range of study and good response to any variations in kinetic parameters as a single sample is analyzed over the whole range of temperature [2]. Another major advantage of the thermogravimetry method is that it can be used to investigate the devolatilization of coal in both inert and oxidizing atmospheres [3].

Thermal decomposition of coal is too complex a study to be expressed in one single chemical reaction. A series of planned tests by researchers has attempted to conclude that decomposition occurs evenly throughout the volume of the particles as a first-order reaction and its length of progress is determined by the chemical structure of coal [4] [5]. The reaction rate for non-isothermal experiments depends on both $f(x)$ and $k(T)$, hence it is imperative to determine one of the kinetic triplets prior to analyzing non-isothermal experiments. A general objective of this work is to model the data generated from thermally activated reactions so as to derive a complete description of the progress of the reaction that may be valid for non-isothermal treatment.

Pseudo first-order reaction rate coefficients are obtained for the combustion of coal under changing heating rates in oxidizing conditions. Literature presents extensive work on the combustion behavior of coal [6] [7]. The combustion process of coal involves mass change with respect to temperature making it crucial to understand the thermo-gravimetric analysis [8]. The mass change vs. temperature profile is used to determine kinetic parameters of coal conversion process at changing heating rates. These parameters are important as they help to determine the optimum conditions for designing a coal-fired boiler [9] [10]. The combustion of coal is generally a scombination of the two processes. One is the pyrolysis or devolatilization of the coal due to applied thermal stress which is a fast process. The second is the heterogeneous combustion of the remaining char which 
is a slow process. The maximum mass loss occurs during the devolatilization stage $\left(400^{\circ} \mathrm{C}-700^{\circ} \mathrm{C}\right)$ of the coals, where mainly $\mathrm{CO}_{2}, \mathrm{CO}, \mathrm{H}_{2} \mathrm{O}$ and a small amount of $\mathrm{CH}_{4}$ are released in oxygen ambience.

Iso-conversional methods are preferred to the traditional statistical model-fitting methods due to inability of the latter to uniquely determine the reaction model. In the case with isothermal experiments when the data is inadequate with incomplete extent of conversion and varies greatly with different experiments, the iso-conversional principle is fundamentally inapplicable. As the iso-conversional or "model-free" calculation methods generate variable activation energy as a function of reaction progress, there have been a lot of controversies surrounding it. This concept of variable activation energy is seen for both isothermal and nonisothermal kinetic experiments. Ammar Khawam [11] investigated the desolvation reaction of solvates of sulfameter (5-methoxysulfadiazine), both isothermally and non-isothermally and established a relationship between desolvation kinetic parameters (e.g. activation energy) and the solvent size. He found that the activation energy responded directly to the size of the solvent molecule. Lastly, it was seen that the kinetic parameters obtained isothermally and non-isothermally did not concur.

As characterized by Smith et al. [12], the coal combustion occurs in four different zones with four distinct activation energies. Zone 1 describes low-temperature combustion where light volatiles are combusted. In this zone, the rate of mass loss is governed by the rate of chemical reaction. Zone 2 marks the beginning of the diffusion of heavier volatiles through the pores in the coal. The reaction rate is controlled by the rate of diffusion through the pores. Zone 3 displays a transition between a process controlled by chemical reaction and pore diffusion. Zone 4 is dominated by high-temperature combustion, where the rate of chemical reaction is higher than the rate of diffusion. Therefore, the combustion in this zone is controlled by pore diffusion [13]. To increase the efficiency of power plants and to enhance the utilization of the burning properties of coal, it becomes increasingly important to learn how coal macerals show different properties under specific conditions [12]. Maceral composition and mean reflectance are considered to be important parameters influencing the coal combustion characteristics. Vitrinite is generally the most reactive maceral and inertinite the least reactive, due to its aromatic nature [13]. However, Bayers et al. proposed with his work that inertinite is slightly more reactive than vitrinite. He added that the reduction in the reactivity is caused due to the rank of the coal and its associated properties i.e. volatility, O/C ratio, H/C ratio, vitrinite reflectance [14] [15] [16]. Bayers et al. also found that the total reflectance value appears to be a better criterion than the percentage of inertinites to distinguish between reactive and nonreactive inertinites. Kissinger [17] [18] investigated the combustion behavior of the Indian coals of four different ranks and found the reactivity of inertinite towards combustion to be better. This diversity calls for a further investigation into the understanding of the combustion characteristics and the kinetics of coal. 
This work presents a study on the combustion of Jamadoba coal through thermal analysis. Efforts have been made to eliminate effects external to the reacting particles so that the conditions are favorable for any coal combustion system. However, a comprehensive understanding of the association of mineral matter of coal to its coaly matrix and assessing whether the combustion reaction characteristics of the individual maceral group governs the reaction characteristics of the parent coal from a range of coals of different ranks and origins is a relatively new dimension [19]. The main purpose of this study is to examine the chemical kinetic performance of the same rank Indian coal, together with the estimation of activation energy and pre-exponential factor and its influence over a range of vitrinite content, inertinite content and heating rate. Non-isothermal thermogravimetric method [20] [21] has been applied to determine the chemical kinetic parameters assuming that coal combustion is a pseudo first-order reaction regarding the loss of weight of the sample.

\section{Materials and Methods}

\subsection{Preparation of Coal Samples}

The parent coal was obtained from Jamadoba washery of the Jharia group that supplies around 0.5 million tones/annum of clean coal to the steelmaking industries for coke making processes. The region lies in the Jharkhand coal belt which is in the eastern part of India. Jharia comprises of five underground coal mines which is spread over two locations $20 \mathrm{kms}$ apart namely Jamadoda and Sijua groups. The Jharia group is one of the best prime coking coals available in India for conventional coke making process. Prime coking coal, when combusted, generates the same amount of electricity for a lower feed compared to the other Indian thermal coals. Other advantages include lowering of $\mathrm{CO}_{\mathrm{x}}$ and particulate emissions and utilization of less efficient ESPs to deal with less generated particulate matter. It was thus chosen as the experimental sample in the present study. The samples were crushed into particle sizes of $(-3+1 \mathrm{~mm},-1+0.5 \mathrm{~mm}$ and $-0.5 \mathrm{~mm}$ ) using jaw crusher and planetary ball mill as per IS 437: 1979 in the coal characterization unit of CSIR-National Metallurgical Laboratory, India. Appropriate samples were taken for detailed characterization. In this study -0.5 $\mathrm{mm}(500 \mu \mathrm{m})$ particle size group was chosen, as it closely corresponds to the particle sizes used in the pulverized coal fired boilers without much liberation of the minerals associated with the organic coal matrix. This size group was subjected to washability test using the float and sink technique. The method for obtaining the density fractions consisted of the separation of approximately $1 \mathrm{~kg}$ of the parent Jamadoba coal using the aforementioned float and sink technique with a mixture of Benzene $\left(0.87 \mathrm{~g} / \mathrm{cm}^{3}\right)$ and Bromoform $\left(2.89 \mathrm{~g} / \mathrm{cm}^{3}\right)$ as dense media. Densities ranged from $1.4 \mathrm{~g} / \mathrm{cm}^{3}$ to $1.2 \mathrm{~g} / \mathrm{cm}^{3}$ and the three sink fractions were labeled as Coal S1.4 at $1.4 \mathrm{~g} / \mathrm{cm}^{3}$, Coal S1.3 at $1.3 \mathrm{~g} / \mathrm{cm}^{3}$ and Coal S1.2 at 1.2 $\mathrm{g} / \mathrm{cm}^{3}$ besides the parent coal sample, Raw HC. After separation, the coal particles were washed with benzene and air dried for a day (at about $110^{\circ} \mathrm{C}$ and $40 \%$ 
humidity) before performing any chemical analysis. Densities of 1.4, 1.3, 1.2 $\mathrm{g} / \mathrm{cm}^{3}$ and parent coal were chosen for the following kinetics study due to their strong correlation with the organic content of the coal.

\subsection{Chemical Characterization of Coal Samples}

The chemical characterization of the experimental samples was carried out at the coal characterization lab of CSIR-National Metallurgical Laboratory, India. Proximate analysis on air dried basis was determined using TGA-1000 automated proximate analyzer (Navas Instruments, USA) while Vario EL III CHNS analyzer (Elementar GmbH, Germany) was used for Ultimate analysis. Proximate and Ultimate analysis were performed on the washed and the raw coal samples together as per the method IS: 1350 (Part 1) and IS: 1350 (Part 4) respectively. The results of the analyses are shown in Table 1 and Table 2.

Petrography analysis of the density separated coal samples was done for reflectance measurement and maceral composition i.e. the percentage of vitrinite, liptinite, inertinite and mineral matter. Maceral identification was based on the ICCP classification (ICCP 1963, 1971, 1978, 1998, 2001) of coal following BIS procedure (IS-9127) on polished mounts under the polarized light microscope (Leica DM4500). The result of the petrography analysis is given in Table 3.

Table 1. Proximate analysis of raw coal and macerals (weight \%).

\begin{tabular}{cccccc}
\hline Sample & Weight & Moisture & Volatiles & Ash & Fixed Carbon \\
\hline Raw HC & 0.9595 & 1.332 & 20.585 & 16.831 & 61.253 \\
CoalS1.4 & 0.5650 & 1.728 & 20.002 & 14.038 & 64.232 \\
CoalS1.3 & 0.9744 & 1.059 & 23.304 & 6.016 & 69.621 \\
CoalS1.2 & 0.9972 & 1.050 & 25.077 & 1.786 & 72.086 \\
\hline
\end{tabular}

Table 2. Ultimate analysis results.

\begin{tabular}{cccccc}
\hline Sample & $\mathrm{N}(\%)$ & $\mathrm{C}(\%)$ & $\mathrm{H}(\%)$ & $\mathrm{S}(\%)$ & $\mathrm{O}(\%)$ \\
\hline Raw HC & 1.73 & 73.67 & 4.1 & 0.63 & 19.87 \\
CoalS1.4 & 1.89 & 75.99 & 4.20 & 0.57 & 17.35 \\
CoalS1.3 & 2.11 & 82.52 & 4.70 & 0.75 & 9.92 \\
CoalS1.2 & 2.22 & 87.30 & 5.16 & 0.81 & 4.52 \\
\hline
\end{tabular}

Table 3. Petrograhical analysis of coal sample (vol \%).

\begin{tabular}{ccccccc}
\hline Sample & Vitrinite & Liptinite & Inertinite & Mineral Matter & Heat Affected & Reflectance (\%) \\
\hline Raw HC & 46.8 & 0.8 & 37.6 & 7.2 & 8.4 & 1.25 \\
CoalS1.4 & 56.3 & 0.4 & 26.3 & 1.2 & 15.8 & 1.31 \\
CoalS1.3 & 79.9 & NA & 10.1 & 0.7 & 9.3 & 1.21 \\
CoalS1.2 & 95.2 & NA & 3.5 & NA & 1.3 & 1.17 \\
\hline
\end{tabular}


The thermogravimetry analysis of the coal samples were performed in the THERMAX 700 system (Thermo-Fishers Scientific Private India Limited, Germany) at the coal characterization unit of CSIR-National Metallurgical Laboratory, India. Non-isothermal TG was applied in determining the chemical kinetic parameters in coal combustion. A particular Indian mineral coal from the Jharkhand coal belt was utilized. It is a raw bituminous low ash, low sulphur and high mean reflectant coal. The analyses were carried out under $80 \mathrm{ml} / \mathrm{min}$ air flow at a heating rate of $\left(2^{\circ} \mathrm{C} / \mathrm{min}, 5^{\circ} \mathrm{C} / \mathrm{min}\right.$ and $\left.7^{\circ} \mathrm{C} / \mathrm{min}\right)$ from room temperature to $1400^{\circ} \mathrm{C}$. Coal samples of $35 \mathrm{mg}$ and $-500 \mu \mathrm{m}$ mean size were weighed and dispersed flatly on crucibles, which had flat bottoms. A small amount of sample and a slow heating rate is adopted to avoid temperature gradients throughout the sample and minimize mass transfer effects. The raw samples were grinded, mixed and homogenized by sieving before proceeding with the TG/DTG experiments to minimize thermal lag between the furnace and sample temperature. Duplicate experiments for each test were performed in order to check the reproducibility of the results. The mass loss and derivative curves of the samples, represented as a function of temperature, exhibits the thermal behavior of coal.

\subsection{Kinetic Analysis}

Over the past decades a bewildering range of methods have been proposed in literature for extracting kinetic knowledge from thermogravimetric analysis (TGA). There are two groups of methods used to analyze isothermal or non-isothermal solid state kinetic data: model-fitting and model-free methods [22] [23] [24] [25]. In the model-fitting method, activation energy (Ea) and frequency factor (A) are calculated from the experimental data fitted into the best statistical model, assumed judicially. Many researchers argue upon the fact that model-free iso-conversional methods are the most reliable methods for the calculation of activation energies of thermally activated reactions. In the process to best characterize the kinetics of solid-state reactions, researchers judiciously choose simplified models based on a single irreversible reaction of the thermal decomposition of coal [26] [27] and assume that the conversion rate during a reaction is the product of two functions, one depending solely on temperature, $T$, and the other depending solely on fraction converted $x$ [28].

The thermal decomposition of coal can be expressed by the following reactions:

$$
\begin{aligned}
& \text { Coal } \stackrel{k}{\longrightarrow} x(\text { volatiles })+(1-x)(\text { char }) \\
& -r_{\text {coal }}=k C_{\text {coal }} \\
& -r_{\text {coal }}=\frac{\mathrm{d} x}{\mathrm{~d} t}=k(1-x)
\end{aligned}
$$

Using conversion fraction, the Equation (2.2) can be written as:

$$
-\ln (1-x)=k t
$$

The global expression for thermal decomposition of a solid sample is: 


$$
\frac{\mathrm{d} x}{\mathrm{~d} t}=f(x) k(T)
$$

where $x$ is the degree of conversion representing the fraction of converted volatiles at time $t, f(x)$ is differential reaction model and $k(T)$ is the reaction rate constant at temperature $T$.

The temperature dependence of reaction rate constant $k(T)$ generally obeys the Arrhenius equation:

$$
k=k_{0} \exp -\left(\frac{E_{a}}{R T}\right)
$$

The degree of conversion is defined in terms of the change in mass of the sample:

$$
x=\frac{W_{o}-W_{t}}{W_{o}-W_{\infty}}
$$

where $W_{o}$ is the initial weight of the solid sample, $W_{\infty}$ is the final weight and $W_{t}$ is the weight of the sample at time $t$.

Finally, the rate equation for an elementary solid state reaction can be written as:

$$
\frac{\mathrm{d} x}{\mathrm{~d} t}=A \mathrm{e}^{-\frac{E_{a}}{R T}} f(x)
$$

Thus, to characterize the overall progress of the reaction at all temperatures and for all temperature-time programmes, the reaction rate function $f(x)$, reaction rate constant $k_{0}$ and activation energy $E_{a}$ (better known as the kinetic triplets) need to be determined. There are two approaches utilized to obtain solid-state kinetic data, namely, isothermal and non-isothermal methods. During isothermal process, samples are studied at constant temperatures over several lengths of time to produce $x$-time data while non-isothermal method employs a linear heating rate to produce $x$-temperature data.

\subsubsection{Isothermal Model-Fitting Method}

This method involves two fits: the first helps in determining the rate constant $(k)$ of the model by utilizing the equation:

$$
g(x)=k t
$$

where $g(x)$ is integral reaction model, $k$ is the reaction rate constant and $t$ is time period.

While the second, helps to determine the kinetic parameters such as the activation energy $(\mathrm{Ea})$ and frequency factor $(\mathrm{A})$ by utilizing the Arrhenius equation:

$$
k=A \mathrm{e}^{-\frac{E_{a}}{R T}}
$$

where $A$ is pre exponential frequency factor, $E_{a}$ is activation energy and $T$ is absolute temperature.

\subsubsection{Non-Isothermal Model-Fitting Method}

There are two ways of defining a non-isothermal method, differential and integral. The differential form of non-isothermal is expressed as follows: 


$$
\frac{\mathrm{d} x}{\mathrm{~d} T}=\frac{\mathrm{d} x}{\mathrm{~d} t} \cdot \frac{\mathrm{d} t}{\mathrm{~d} T}
$$

where $\mathrm{d} x / \mathrm{d} T$ is the non-isothermal reaction rate, $\mathrm{d} x / \mathrm{d} t$ is the isothermal reaction rate and $\mathrm{d} t / \mathrm{d} T$ is the reciprocal of heating rate, $\lambda$.

Substituting Equation (2.7) into Equation (2.10)

$$
\frac{\mathrm{d} x}{\mathrm{~d} T}=\frac{A}{\lambda} \mathrm{e}^{-\frac{E_{a}}{R T}} f(x)
$$

Integrating the differential form of non-isothermal Equation produces the integral form of non-isothermal rate law (also known as the temperature integral), which is expressed as:

$$
g(x)=\frac{A}{\lambda} \int_{0}^{T} \mathrm{e}^{-\frac{E_{a}}{R T}} \mathrm{~d} T
$$

There are many model-fitting methods (a few of them listed below) that utilize non-isothermal data to extrapolate kinetic triplets ( $A, E_{a}$ and model). However, the sole use of these methods is not recommended as they assume a constant kinetic triplet and involve a single heating rate.

\subsubsection{Model-Free Methods}

Model-Free methods usually report activation energies as they calculate the reaction activation energy $\left(E_{a}\right)$ without any modelistic assumptions. Methods of activation energy analysis require the determination of the temperatures, $T_{x}(\lambda)$, at an equivalent stage of the reaction for various heating rates. Hence the term iso-conversion method is used. The equivalent stage is one where fixed fraction of the total amount is transformed [29]. Iso-conversional methods are model-free methods that evaluate kinetic parameters viz. activation energy $\left(E_{a}\right)$ and pre-exponential factor $(A)$ at progressive extents of conversion $(x)$ [30]. Iso-conversional methods are crucial when it comes to determining solid-state kinetics as they usually follow complex mechanisms including multiple series and parallel stages with different activation energies. The terms "model-free" and "iso-conversional" are sometimes used interchangeably, but this does not imply that all model-free methods are iso-conversional [31]. Traditionally, model-fitting methods were widely used to calculate the kinetic parameters directly from the TGA analysis results. However, growing concern surrounding the inadequacy to uniquely select the most fitting reaction model, has led to the decline of this method in favour of iso-conversional (model-free) methods [32]. Furthermore, in the case of non-isothermal data, comparing the results of the model-fitting methods in the literature can be difficult as it covers a wide range of kinetic parameters for coal combustion process [33]. Advantages to iso-conversional methods are prompt ways to determining kinetic parameters for complex reaction profiles involving multiple processes and avoidance of errors while selecting specific reaction models.

Non-isothermal iso-conversional methods can be categorized into two main 
groups. The first set of group involves the approximation of temperature integral i.e. requiring data based only on $T_{x}(\lambda)$, which is the temperature at an equivalent (fixed) state of transformation for various heating rates. Methods in this group include the Kissinger method, the Kissinger-Akahira-Sunose method and the Flynn-Wall-Ozawa method. The second set of group contains methods that determine reaction rates at an equivalent stage of the reaction for various heating rates. A well-known method of this group is the Friedman method.

\section{1) Kissinger Method}

The method of Kissinger [17] uses non-linear weight loss of a sample to determine the kinetic parameters of its decomposition reaction, with respect to reaction temperature. This is a model-free method but not an iso-conversional one as it assumes constant activation energy throughout the progress of the reaction. The Kissinger method is expressed as:

$$
\ln \left(\frac{\lambda}{T_{p}^{2}}\right)=-\frac{E}{R T_{p}}+\ln \left(\frac{A R}{E}\right)
$$

where $T_{p}$ corresponds to the temperature at maximum weight loss rate of the coal sample. Kinetic parameters including activation energy $\left(E_{a}\right)$ and pre-exponential factor $(A)$ can be obtained from a plot of $\ln \left(\lambda / T_{p}^{2}\right)$ versus $1000 / T_{p}$ for a series of experiments at different heating rates.

\section{2) Kissinger-Akahira-Sunose Method}

This method is sometimes called the generalized Kissinger method [18]. It is said to be one of the best known methods in applying the approximation of temperature integral to calculate kinetic parameters. This method uses the Murray and White approximation for temperature integral to propose the following expression:

$$
\ln \left(\frac{B}{T^{2}}\right)=\ln \left(\frac{A R}{E_{a} g(x)}\right)-\frac{E_{a}}{R T}
$$

where $g(x)$ is the reaction model integral conversion function. According to the above equation, a plot of $\ln \left(\lambda / T^{2}\right)$ versus $1000 / T$ at different heating rates results in straight lines, the slope of straight lines equaling $E_{a} / R$.

\section{3) Flynn-Wall-Ozawa Method}

The Flynn-Wall-Ozawa method [34] [35] [36] [37] [38] is an independently developed iso-conversional method for non-isothermal process. This method uses Doyle's approximation to give the following equation:

$$
\ln (\lambda)=\ln \left(\frac{A E_{a}}{R g(x)}\right)-5.331-1.052 \frac{E_{a}}{R T}
$$

A plot of $\ln (\lambda)$ versus $1000 / T$, for a constant conversion at different heating rates, will be a straight line whose slope $\left(-1.052\left(E_{a} / R T\right)\right)$ will calculate the activation energy.

The Kissinger, the Kissinger-Akahira-Sunose and the Flynn-Wall-Ozawa methods involve the plotting of $1000 / T$ versus a logarithmic function which de- 
pends on the heating rate and/or the temperature. The logarithmic function depends on the approximation of the temperature integral used, which is different for each one of them [38].

\section{4) Friedman Method}

This method is a differential form of the isothermal rate law which can be put as:

$$
\frac{\mathrm{d} x}{\mathrm{~d} T}=\frac{A}{\lambda} \exp \left[-\frac{E_{a}}{R T}\right] f(x)
$$

Using natural logarithm on both sides of the isothermal rate law, the expression proposed by Friedman can be presented as:

$$
\ln \left(\frac{\mathrm{d} x}{\mathrm{~d} t}\right)=\ln \left(\lambda \frac{\mathrm{d} x}{\mathrm{~d} T}\right)=\ln A+\ln [f(x)]-\frac{E_{a}}{R T}
$$

The activation energy $\left(E_{a}\right)$ is determined from the slope of the plot of $\ln (\mathrm{d} x / \mathrm{d} t)$ versus $1000 / T$ for a constant conversion value of $x$. Pertaining to the non-isothermal approach of the study, each run was conducted under the same experimental conditions (with regards to sample weight, sample size and purge gas rate), leaving heating rate as the only varying condition. Low heating rates have been considered for the experiment runs so as to procure accurate results with high certainty. This paper focuses largely on the accuracy of methods for obtaining the activation energy from experiments at constant heating rate, $\lambda$.

\section{Results and Discussions}

\subsection{Coal Quality and Mineralogy}

In the present study, quality of the coal samples was evaluated by performing proximate, ultimate and petrography analysis. Results obtained from proximate and ultimate analysis of different density fraction of the coal samples viz. Raw Coal, Coal S1.4, Coal S1.3 and Coal S1.2 are summarized in Table 1. Proximate and ultimate analyses have been reported on air-dried basis.

Coal samples selected for this study are of high quality with very low ash content $(1.7 \%-16.8 \%)$, high fixed carbon content $(61.2 \%-72.1 \%)$, high vitrinite content $(46.8 \%-95.2 \%)$ and high mean reflectance value $(1.17 \%-1.31 \%)$.The volatile matter of the coals varies from $20.5 \%-25.07 \%$ with Coal S1.2 having the highest value, suggesting the presence of high volatile organic compounds. Following the investigation of coal petrography, results of the coal samples as outlined in Table 2 suggest that Coal S1.2, Coal S1.3 and Coal S1.4 are almost organic coal free from mineral matter. However, total sulphur content is relatively low $(0.63 \%-0.81 \%)$ and majority of the sulphur is associated with the coal macerals i.e. organically associated sulphur. Coal S1.2 has the highest percentage of sulphur, hence corroborating the presence of organically associated sulphur. Results summarized in Table 1 \& Table 2 indicate that among the four selected coal samples for this study, Coal S1.2 is of the best quality with the highest fixed carbon content $(72.1 \%)$, the lowest ash content (1.7\%), highest vitrinite 
content (95.2\%), highest volatile matter (25.07\%) and negligible mineral matter.

\subsection{Thermogravimetric Analysis of Coal Samples under Air Atmosphere}

Combustion is a complex process and the presence of oxygen triggers gas-phase reactions between low temperature volatiles and oxygen and combustion of char generated in the early stages of decomposition [6]. Literature proposes two independent reactions responsible for thermal degradation of coal and/or biomass under an oxidative atmosphere. The two-stage kinetic reactions can be illustrated as:

$$
\begin{aligned}
& \mathrm{A}(\text { solid }) \rightarrow \mathrm{B}(\text { char })+\mathrm{C} 1(\text { gas }) \quad \text { (first stage }) \\
& \mathrm{B}(\text { char }) \rightarrow \mathrm{C} 2(\text { gas })+\mathrm{D}(\text { ash }) \quad \text { (second stage })
\end{aligned}
$$

As this kinetic study of Indian sub-bituminous coking coal utilizes washed coal of density fractions 1.4, 1.3 and 1.2; a dual behavior (biomass and coal) of thermal decomposition is highly anticipated. This assumption is supported by the petrography analysis which has determined the mineral matter in these samples to be slightly above $1 \%$ (See Table 2).

Coal S1.4 contains a mineral matter content of $1.2 \%$ compared to $0.7 \%$ and $1.3 \%$ in Coal S1.3 and Coal S1.2 respectively. As the coal is washed, higher density elements such as Fe and $\mathrm{Zn}$ (and the sulphur bound to them) are selectively removed and the coal is enriched in the lowest density fractions. These near-density or lowest density washed coal fractions are very rich in organically bonded long chain hydrocarbons (both aromatic and aliphatic) and clusters of aromatic carbon with few side chains linked to the coal macromolecule. As the sulphur is organically bonded, it is presumed that these sulphur atoms are acting as bridges between aromatic clusters, which is why the coal sample washed at near-density has a higher sulphur \% than raw coal. The high organic presence in the coal macromolecule makes it challenging to identify the widely known classic "three-zone" (three different temperature zones) theory to interpret experimental data in char oxidation. The raw coal sample, however, has a mineral matter content of $7.2 \%$. The TG and DTG thermograms of the decomposition of Jamadoba coal samples obtained at three different heating rates $\left(2,5\right.$ and $\left.7^{\circ} \mathrm{C} \cdot \mathrm{min}^{-1}\right)$ under air atmosphere are shown in Figures 1-8. The TG curves represent the percentage weight loss of the coal samples over the range of temperature from $300 \mathrm{~K}$ to $1700 \mathrm{~K}$. As shown in Figures the rate of weight loss depends on the temperature; higher the temperature, greater is the weight loss until all the combustible mass is burned. For coal sample, Raw Coal (Figure 1) at heating rates of 2,5 and $7^{\circ} \mathrm{C} \cdot \mathrm{min}^{-1}$, the devolatilization process launches at temperature about $650 \mathrm{~K}$ and proceeds fast with elevating the temperature up to $900 \mathrm{~K}$ after which the weight of the samples drops steadily and progressively with temperature. As the heating rate increases, the temperature of the maximum decomposition rate of Raw $\mathrm{HC}$ is seen to shift towards higher temperature. The equilibrium states attained by 2,5 and $7^{\circ} \mathrm{C} \cdot \mathrm{min}^{-1}$ 


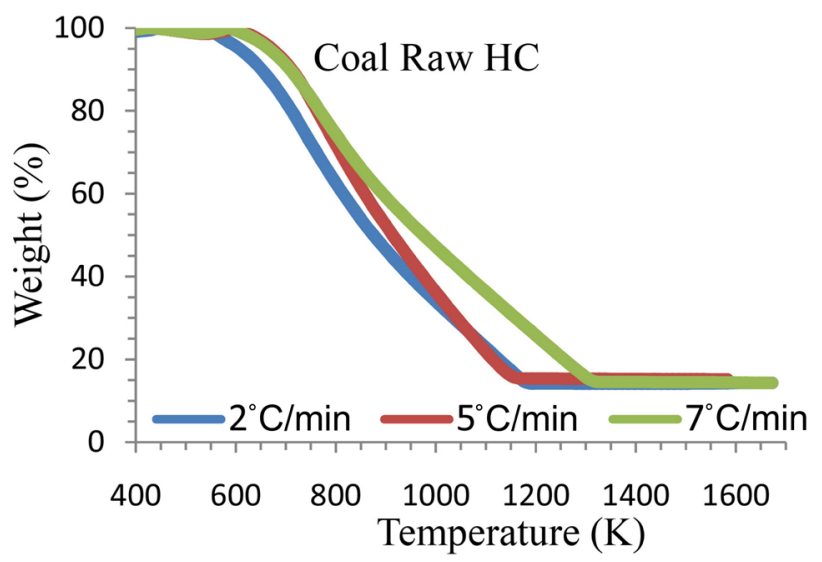

Figure 1. Thermal behavior of Raw HC at different heating rates under air atmosphere.

Coal S1.4

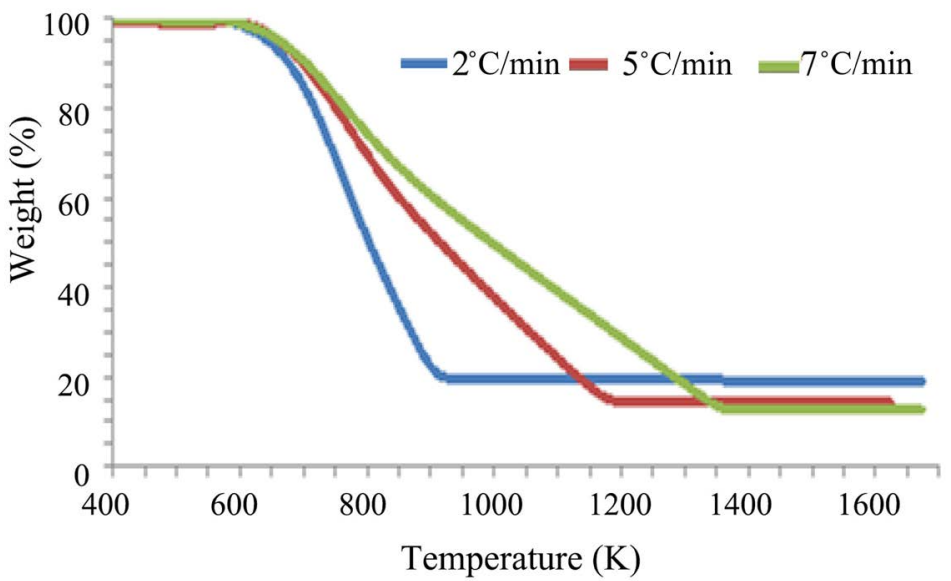

Figure 2. Thermal behavior of Coal S1.4 at different heating rates under air atmosphere.

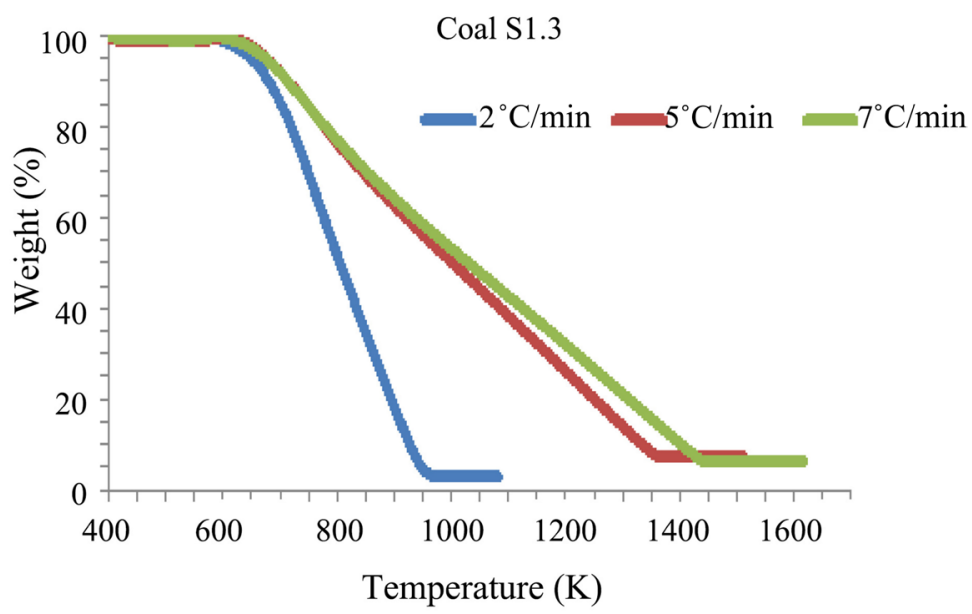

Figure 3. Thermal behavior of Coal S1.3 at different heating rates under air atmosphere.

are 1200,1175 and $1325 \mathrm{~K}$, respectively. From the TGA results the relationship of percentage conversion with temperature has also be attained. 
Coal S1.2

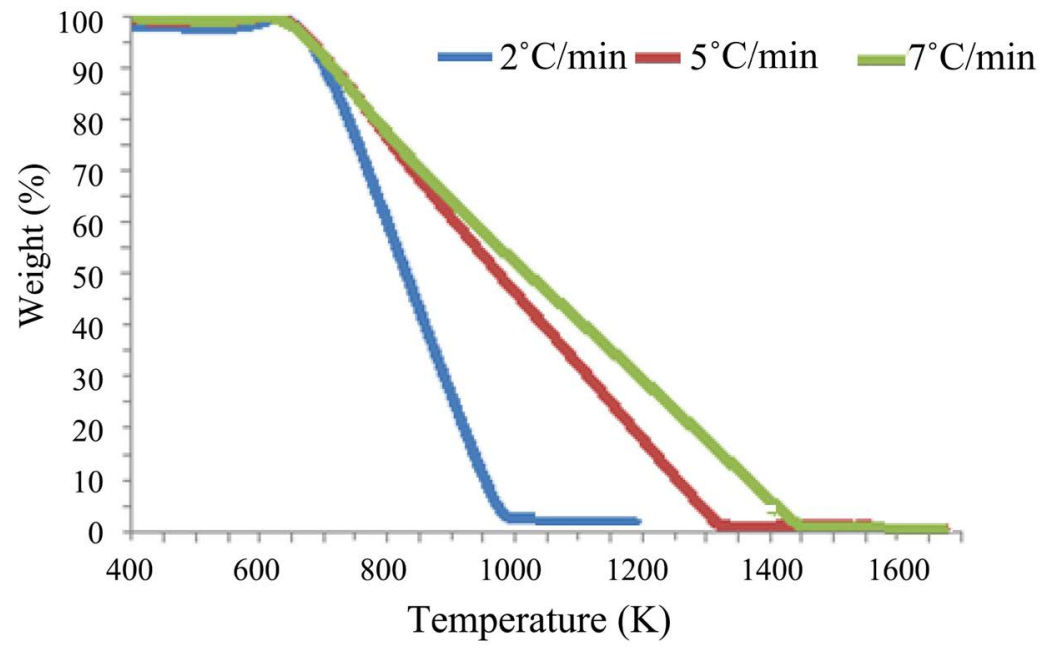

Figure 4. Thermal behavior of Coal S1.2 at different heating rates under air atmosphere.

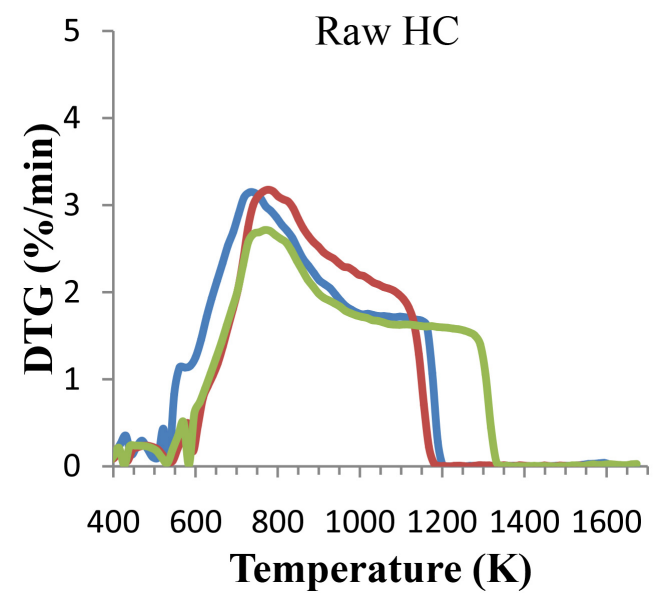

Figure 5. DTG curves of Raw HC at different rates under air atmosphere.

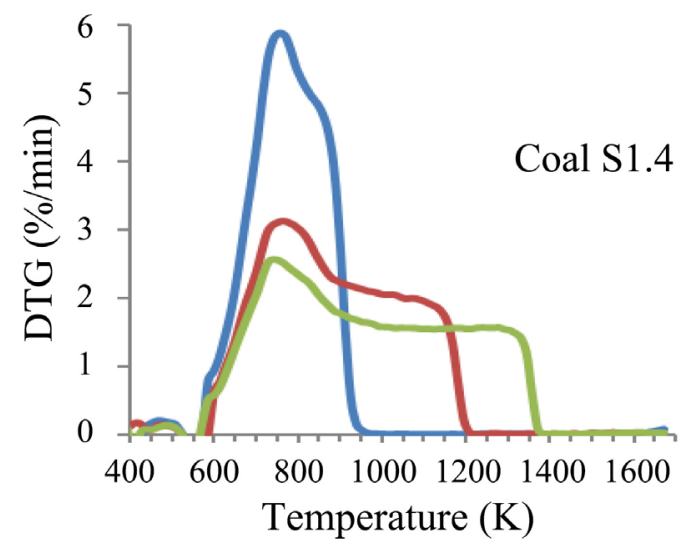

Figure 6. DTG curves of Coal S1.4 at different heating rate under air atmosphere.

For coal sample Coal S1.4 (Figure 2) at heating rates 5 and $7^{\circ} \mathrm{C} \cdot \mathrm{min}^{-1}$, the devolatilization process launches at temperature about $650 \mathrm{~K}$ and proceeds fast 


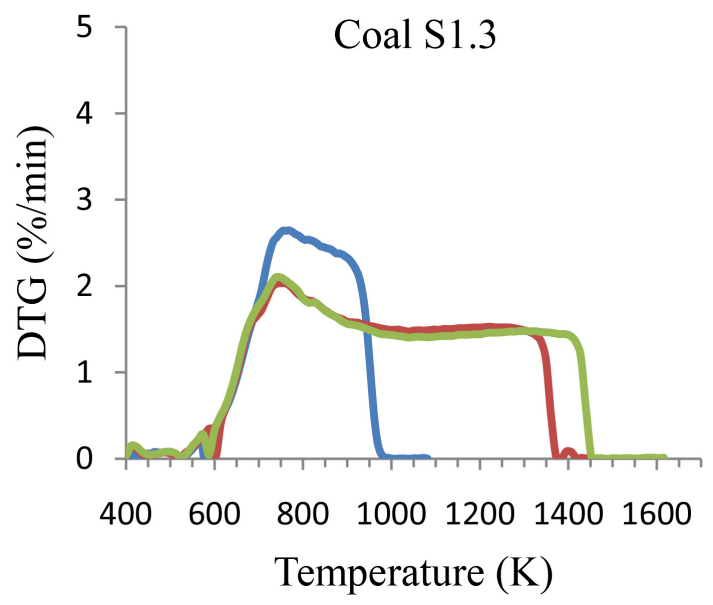

Figure 7. DTG curves of Coal S1.3 at different heating rates under air atmosphere.

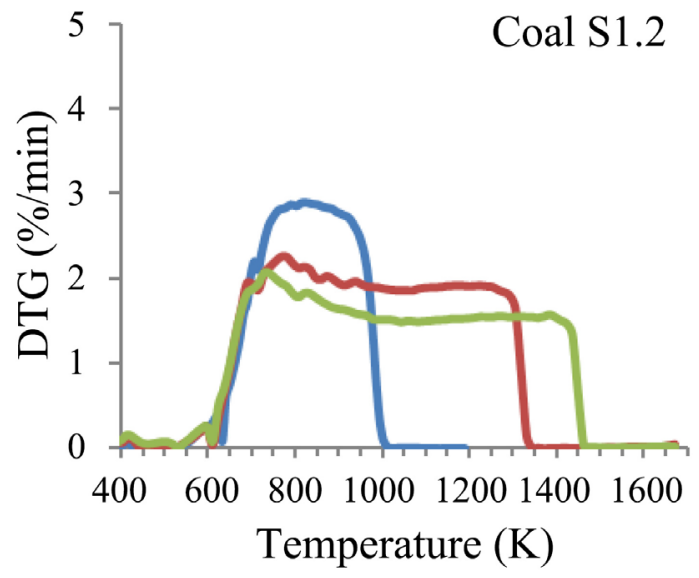

Figure 8. DTG curves of Coal S1.2 at different heating rates under air atmosphere.

with elevating the temperature up to $900 \mathrm{~K}$ after which the weight of the samples drops steadily and progressively with temperature. For heating rate $2^{\circ} \mathrm{C} \cdot \mathrm{min}^{-1}$, there is no such observed devolatilization slope in the TG graph, the loss in weight however starts at $650 \mathrm{~K}$ and is rather acute with increase in temperature of the sample and reaches an equilibrium state much before the other two heating rates, at $950 \mathrm{~K}$. As the heating rate increases, the temperature of the maximum decomposition rate of Coal S1.4 is seen to shift towards higher temperature. The equilibrium states attained by 5 and $7^{\circ} \mathrm{C} \cdot \mathrm{min}^{-1}$ are 1200 and $1400 \mathrm{~K}$, respectively. The relationship of percentage conversion with temperature has been gathered from the TGA results.

The devolatilization process for Coal S1.3 (Figure 3) initiates at temperature about $650 \mathrm{~K}$ and proceeds fast with elevating the temperature up to $900 \mathrm{~K}$ at heating rates for both 5 and $7^{\circ} \mathrm{C} \cdot \mathrm{min}^{-1}$. The drop in sample weight becomes steadier after $900 \mathrm{~K}$. For heating rate of $2^{\circ} \mathrm{C} \cdot \mathrm{min}^{-1}$, there is no such observed devolatilization slope in the TG graph, similar to Coal S1.4, the loss in weight begins at $650 \mathrm{~K}$ and is rather sharp and inclined with increase in temperature of the sample and reaches an equilibrium state much before the other two heating 
rates, at $950 \mathrm{~K}$. With increase in heating rate, the temperature of the maximum decomposition rate of Coal S1.3 shifts towards higher temperature. The equilibrium states attained by 5 and $7^{\circ} \mathrm{C} \cdot \mathrm{min}^{-1}$ are $1375 \mathrm{~K}$ and $1450 \mathrm{~K}$, respectively. A plot of percentage conversion against temperature has been outlined.

Coal S1.2 (Figure 4) starts to devolatilize at $650 \mathrm{~K}$ and proceeds fast with elevating the temperature up to $900 \mathrm{~K}$, analogous to the trend observed for the other three samples, at heating rates for both 5 and $7^{\circ} \mathrm{C} \cdot \mathrm{min}^{-1}$. The drop in sample weight becomes steadier after $900 \mathrm{~K}$. For heating rate of $2^{\circ} \mathrm{C} \cdot \mathrm{min}^{-1}$, there is once again no such observed devolatilization slope in the TG graph, the loss in weight begins at $650 \mathrm{~K}$ and is seen to be sharp and inclined with increase in temperature of the sample and reaches an equilibrium state much before the other two heating rates, at $1000 \mathrm{~K}$. Increasing heating rate evokes the temperature of the maximum decomposition rate of Coal S1.2 to shift towards higher temperature. The equilibrium states attained by 5 and $7^{\circ} \mathrm{C} \cdot \mathrm{min}^{-1}$ are $1325 \mathrm{~K}$ and $1450 \mathrm{~K}$, respectively.

If we carefully observe the TGA graphs of Coal S1.4, we see that the weight loss $\%$ for a heating rate of $2 \mathrm{C} \cdot \mathrm{min}^{-1}$ is the least compared to the other two heating rates. The reason behind this selective weight loss $\%$ is that slow heating causes the carbon containing compounds to burn completely to the pores before reaching the melting temperature of the minerals. Hence, we see a larger amount of unburnt ash for Coal S1.4 when it is heated slowly at $2^{\circ} \mathrm{C} \cdot \mathrm{min}^{-1}$. This hypothesis is reaffirmed when we see the mineral matter content of Coal S1.4, Coal S1.2 and Raw HC. Due to very low mineral matter content, Coal S1.2 does not show a similar trend. However, Raw HC has a very high mineral matter content hence it produces a larger and an invariable ash percentage for all the heating rates. The experimental DTG curves for the coal samples under air atmosphere at different heating rates are shown in Figures 5-8.

For Coal S1.3 (Figure 7), the one-step thermal decomposition reaction begins at $600 \mathrm{~K}$ and proceeds steadily till $975 \mathrm{~K}$ with a peak temperature at $770 \mathrm{~K}$ for a $2^{\circ} \mathrm{C} \cdot \mathrm{min}^{-1}, 1375 \mathrm{~K}$ with a peak temperature at $760 \mathrm{~K}$ for a $5^{\circ} \mathrm{C} \cdot \mathrm{min}^{-1}$ and $1450 \mathrm{~K}$ with a peak temperature at $740 \mathrm{~K}$ for a $7^{\circ} \mathrm{C} \cdot \mathrm{min}^{-1}$ heating rate. A similar inversely proportional trend, to Coal S1.4, of the peak temperature with the heating rates is observed for this sample. For Coal S1.2 (Figure 8), the one-step thermal decomposition reaction begins at $600 \mathrm{~K}$ and proceeds steadily till $1000 \mathrm{~K}$ for a $2^{\circ} \mathrm{C} \cdot \mathrm{min}^{-1}, 1350 \mathrm{~K}$ for a $5^{\circ} \mathrm{C} \cdot \mathrm{min}^{-1}$ and $1450 \mathrm{~K}$ for a $7^{\circ} \mathrm{C} \cdot \mathrm{min}^{-1}$ heating rate with no peak temperatures.

Devolatilization of the sample is strongly dependent on the coal composition and heating rate. Coal S1.4 starts to devolatilize at $600 \mathrm{~K}$ as per the TG and DTG graphs but is soon overlapped by curves of oxidative degradation (i.e. burning of released volatiles) and combustion. This observation holds true for the all other samples. The DTG curves (Figures 5-8) show us that an initial mass loss (stage A) occurs between the temperatures $400 \mathrm{~K}$ and $550 \mathrm{~K}$ at all heating rates, due to moisture evaporation but largely due to surface diffusion from bulk gas (oxygen) to particle surface which is marked by $0.1 \%$ loss in sample weight. This region 
can also be characterized as the first zone. An increase in sample weight\% is seen to occur between $525 \mathrm{~K}$ and $575 \mathrm{~K}$ for Coal S1.4 at all heating rates. This is particularly due to the chemisorption of oxygen onto the coal surface that happens before ignition [39]. In the chemisorption phase, oxygen gets adsorbed on the active site of the particle pores and oxidizes the carbonaceous compounds.

After that, three-step mass losses (stages B, C and D) take place, consecutively, in Raw HC, Coal S1.4 and Coal S1.3 compared to only a one-step mass loss (stage C) for coal sample Coal S1.2. Stage B would be due to desorption and release of the product $\mathrm{CO}$, stage $\mathrm{C}$ is due to oxidative degradation i.e. release of volatiles and their oxidation and stage $\mathrm{D}$ is due to remaining char oxidation. During stage $\mathrm{C}$ major volatile matter is liberated from coal structure in the form of gases such as hydrogen, carbon monoxide, lighter hydrocarbons and small particulates of soot resulting from any incomplete combustion [40]. This region marks the main decomposition stage and is of great significance for further examination as major weight loss and complex chemical reactions take place resulting in the release of tar and gaseous products [41]. The first two mass losses, stages B and C usually happen due to burning of complex organic polymers, phenolic compounds, carboxyl groups and organic carbon containing compounds, whereas the last one, stage $\mathrm{D}$ was mostly due to combustion of the remaining carbonaceous matter.

However, part of the mass loss is due to the coaly matter because the second (stage C) and the third (stage D) decomposition peaks clearly overlap each other. Similarly, part of the mass loss of stage D is due to oxidative degradation of the long chain hydrocarbons. Due to high percentage of low temperature organically bound mineral matter such as carbonates and bicarbonates or hydrates, Coal S1.4 at $2 \mathrm{C} \cdot \mathrm{min}^{-1}$ ceases to burn beyond $950 \mathrm{~K}$. Organically bounded mineral matter is the intrinsic mineral matter that is contained within the organic matrix in the form of chemically bound molecules and submicron crystals, which is not liberated mechanically by grinding. It is this intrinsic mineral matter that forms ash nodules in the pores of the char, when the coal is burned [42].

\subsection{Kinetic Analysis of Coal Samples}

Model-free methods do not require assumptions of kinetic model and the knowledge of the order of the reaction. The differential values $(\mathrm{d} x / \mathrm{d} t)$, corresponding to a fixed fractional conversion $(x)$ are obtained from the DTG plots. Fractional conversion $(x)$ and $(\mathrm{d} x / \mathrm{d} t)$ against temperature have been shown (Figures 9-12) for different coal samples at different heating rates. Activation energy usually refers to the minimum-extra-energy over and above the average potential energy of the reactant molecules required by them to collide with one another so as to reach the transition state. High activation energy is generally encountered during slow reactions while for fast reactions the activation energy is usually low. The value of activation energy for Raw HC increases up to the fractional conversion value of 0.3 and then starts to decrease. After reaching $50 \%$ conversion, the 


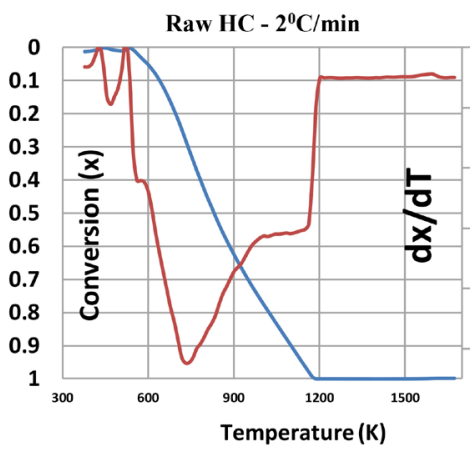

(a)

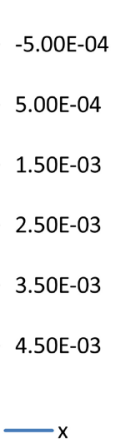

$3.50 \mathrm{E}-03$

OE-03

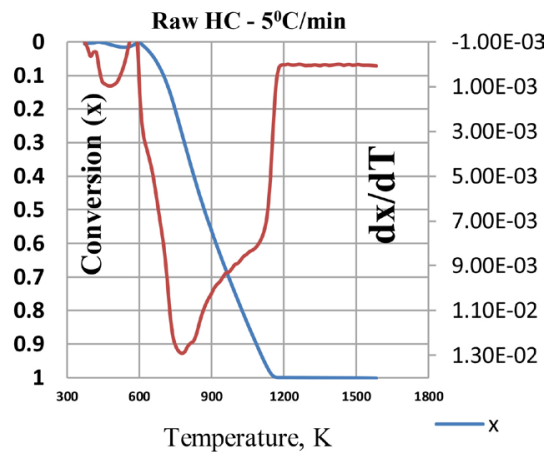

(b)

Raw HC $-7^{\circ} \mathrm{C} / \mathrm{min}$

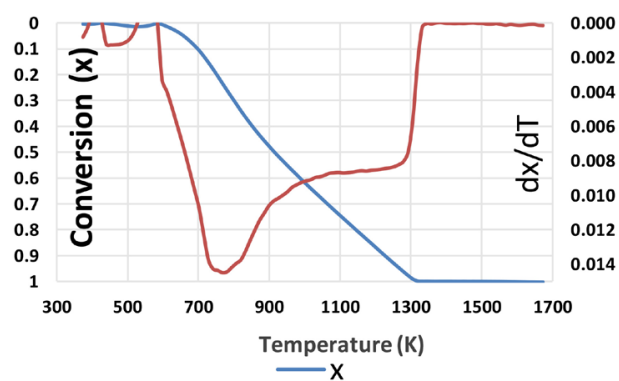

(c)

Figure 9. Plot of fractional conversion $x$ and $\mathrm{d} x / \mathrm{d} T$ against temperature for Raw HC at three different heating rates (a) 2 , (b) 5 and (c) $7^{\circ} \mathrm{C} / \mathrm{min}$.

Coal S1.4 - $2^{\circ} \mathrm{C} / \mathrm{min}$

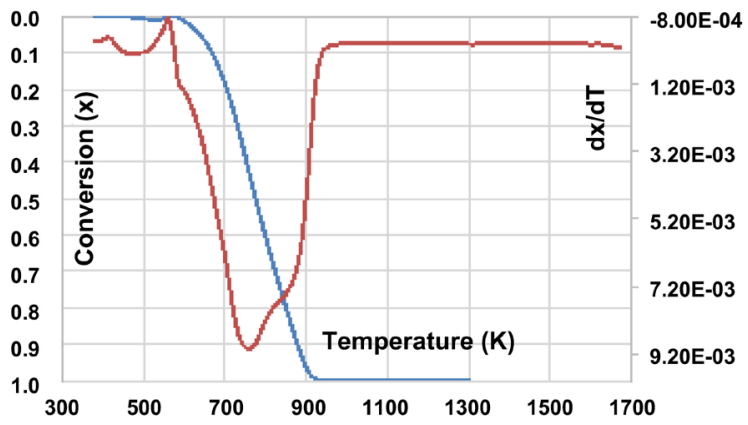

(a)

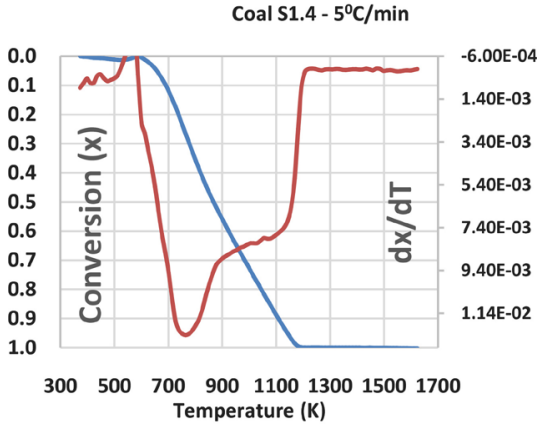

(b)

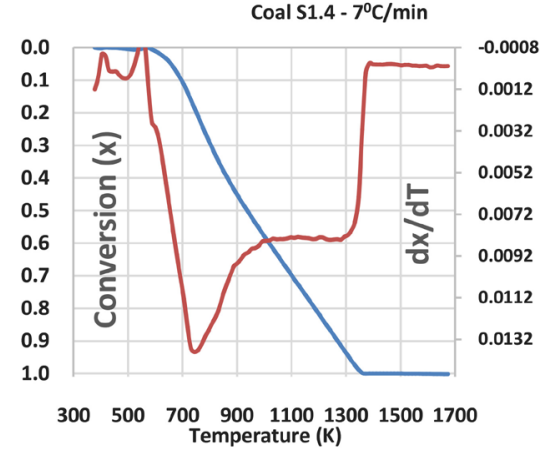

(c)

Figure 10. Plot of fractional conversion $x$ and $\mathrm{d} x / \mathrm{d} T$ against temperature for Coal S1.4 at three different heating rates (a) 2 , (b) 5 and (c) $7^{\circ} \mathrm{C} / \mathrm{min}$. 


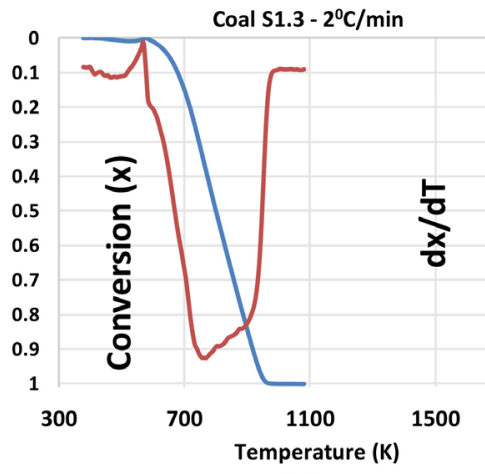

(a)

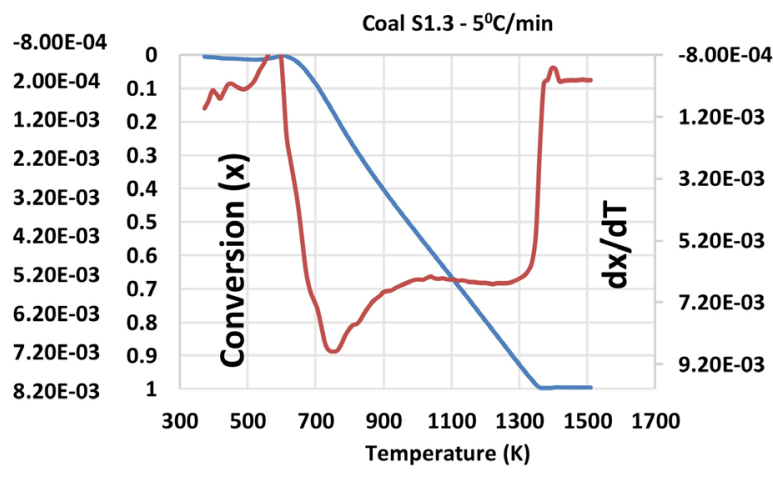

(b)

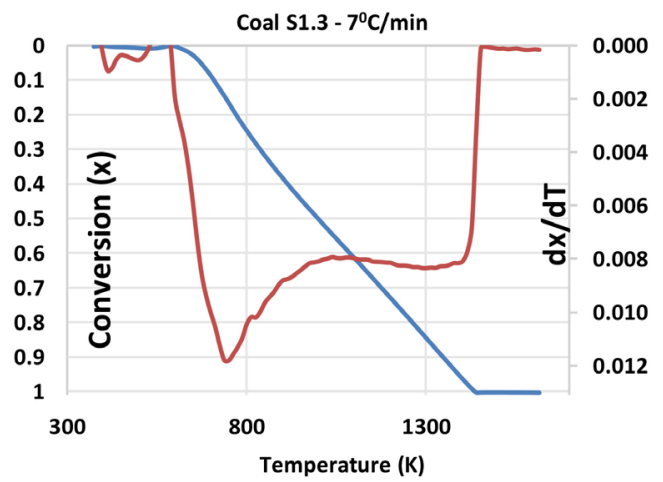

(c)

Figure 11. Plot of fractional conversion $x$ and $\mathrm{d} x / \mathrm{d} T$ against temperature for Coal $\mathrm{S} 1.3$ at three different heating rates (a) 2 , (b) 5 and (c) $7^{\circ} \mathrm{C} / \mathrm{min}$.

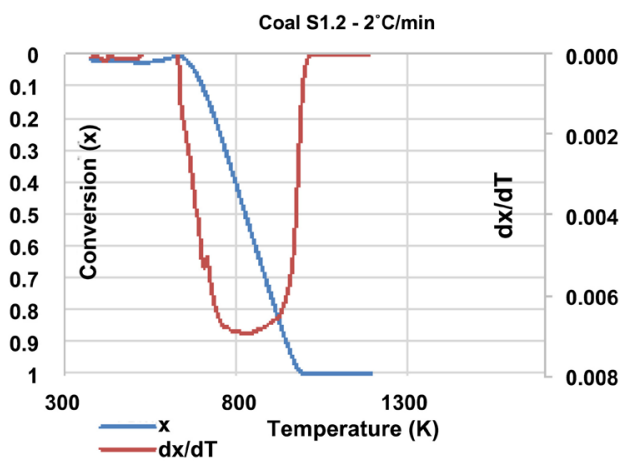

(a)

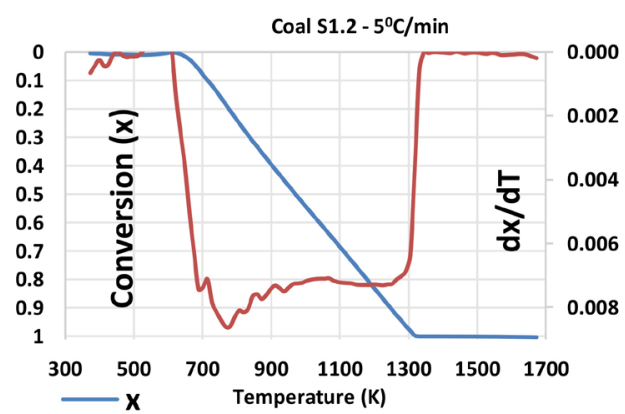

(b)

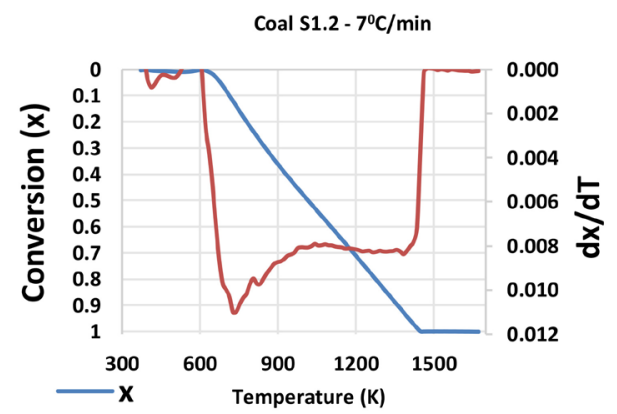

(c)

Figure 12. Plot of fractional conversion $x$ and $\mathrm{d} x / \mathrm{d} T$ against temperature for Coal S1.2 at three different heating rates (a) 2 , (b) 5 and (c) $7^{\circ} \mathrm{C} / \mathrm{min}$. 
activation energy values show poor correlation coefficient of linear fit. Activation energy for Coal S1.4 is seen to fall steadily up to the fractional conversion value of 0.6 after which it noticeably increases. Correlation coefficient is evidently poor in between fractional conversion values of 0.4 and 0.6. Different model-free methods such as Kissinger, conversional methods of Friedman, Ozawa-FlynnOzawa, Kissinger-Akahira-Sunose are used for the evaluation of kinetic parameters from the kinetic data of coal combustion obtained under non-isothermal conditions under air atmosphere. The activation energies and pre-exponential factors were calculated as a function of conversion by adopting these methods (Figures 13-16).

\subsubsection{Friedman Iso-Conversional Method}

Friedman iso-conversional method gives us activation energy values for Coal S1.3

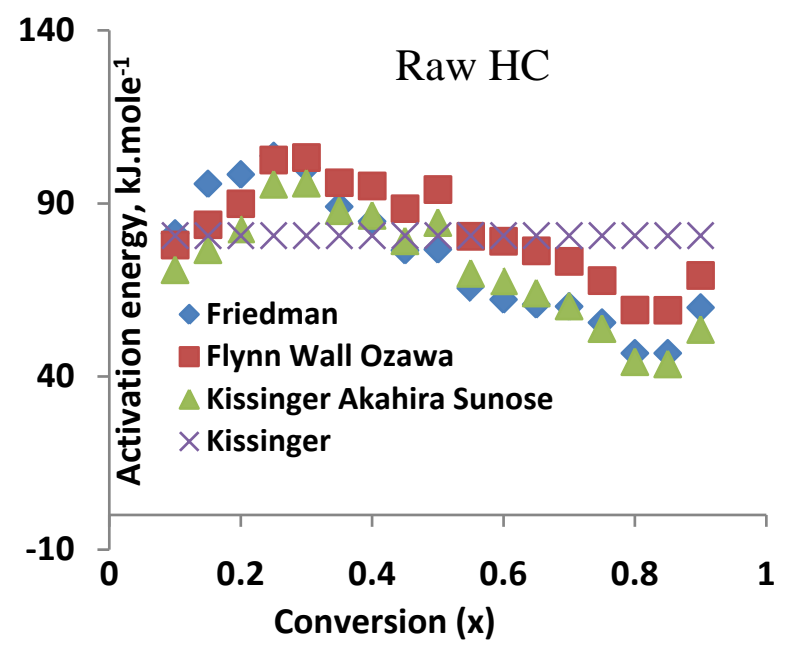

Figure 13. The activation energy as a function of conversion using model-free iso-conversional technique for Raw HC.

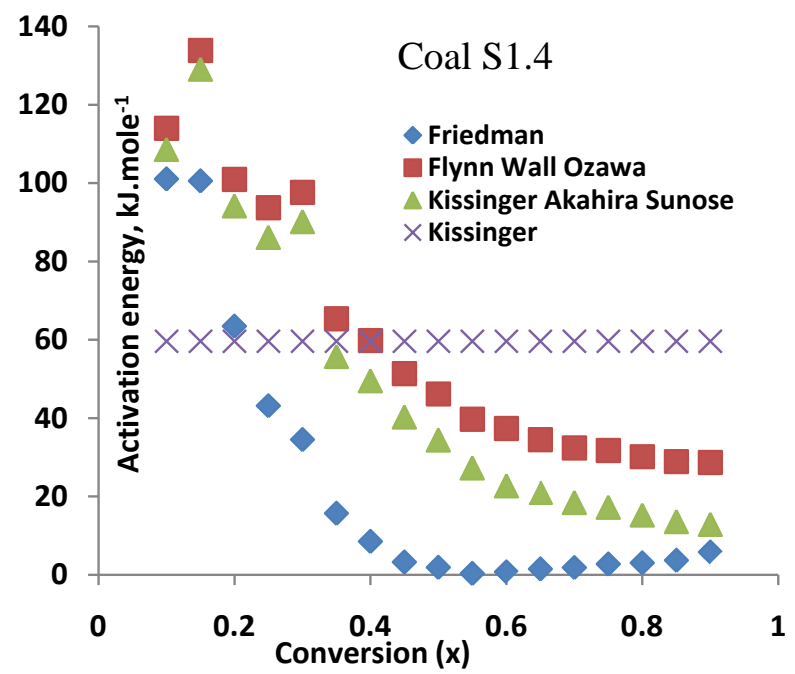

Figure 14. The activation energy as a function of conversion using model-free iso-conversional technique for Coal S1.4. 


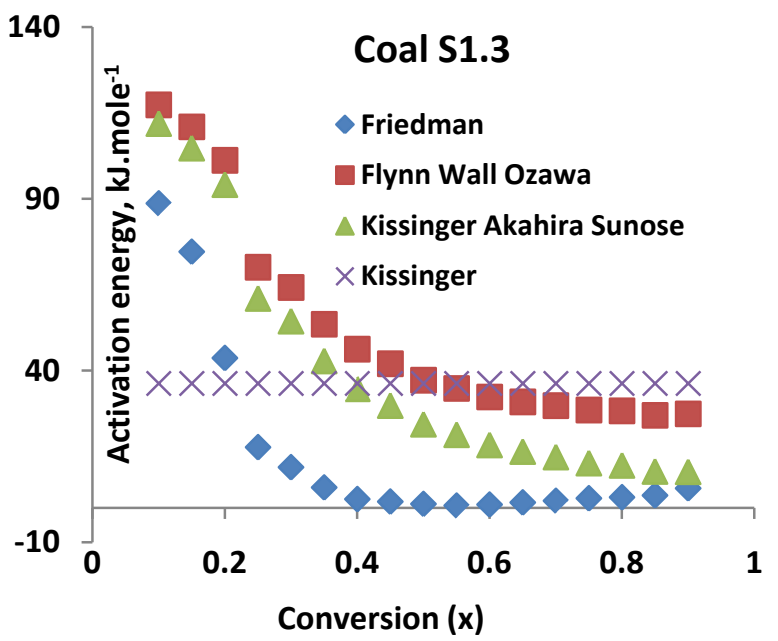

Figure 15. The activation energy as a function of conversion using model-free iso-conversional technique for Coal S1.3.

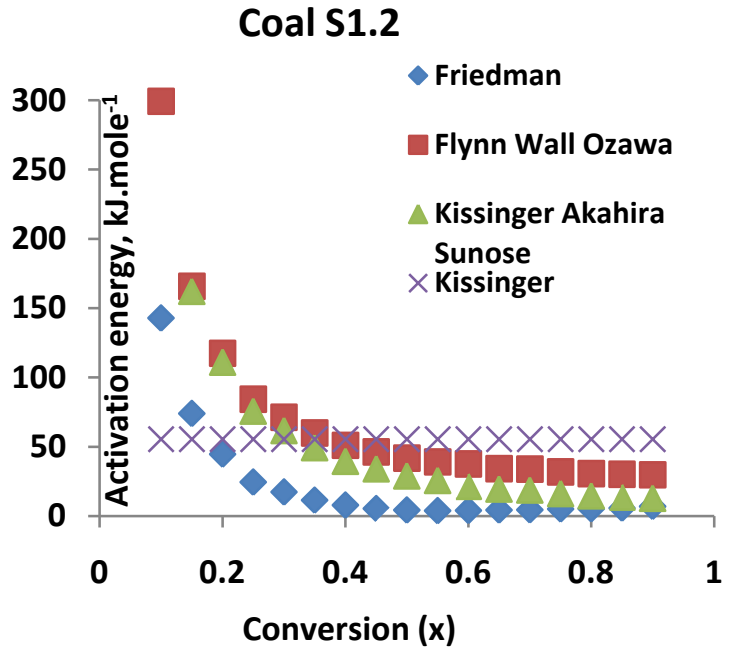

Figure 16. The activation energy as a function of conversion using model-free iso-conversional technique for Coal S1.2.

with very poor correlation coefficient. The value of activation energy for Coal S1.2 decreases steadily to the fractional conversion value of 0.7 and then it remains constant. The activation energy values show reasonably good correlation coefficient of linear fit. The values vary from $143 \mathrm{~kJ} \cdot \mathrm{mol}^{-1}$ to $4 \mathrm{~kJ} \cdot \mathrm{mol}^{-1}$.

\subsubsection{Activation Energy Obtained by Model-Free Methods}

The activation energy values for four coal samples were obtained as a function of conversion by using iso-conversional methods of Friedman, Flynn Wall and Ozawa, Kissinger-Akahira-Sunose, and Kissinger. The iso-conversional plots of the calculated activation energy from different methods are shown in Figures 13-16 respectively. The values of activation energy and other kinetic parameters vary with the methods. Conversion values ranging from 0.1 to 0.9 is considered for calculating the kinetic parameters. It is seen from Figures that the values of 
activation energies are not similar at different conversion values of thermal decomposition, reiterating the fact stated by Vyazovkin and his team of researchers that kinetic parameters may vary with reaction progress in the case of solid state reactions and not obey the widely assumed constant activation energy theory [43]. Variation in activation energy could be due to the heterogeneous nature of the solid sample or due to a complex reaction mechanism. Figures show the dependence of the activation energy on the extent of conversion.

Taking Kissinger-Akahira-Sunose iso-conversional method into account, the activation energy for Coal S1.4 rises from about $110 \mathrm{~kJ} \cdot \mathrm{mol}^{-1}$ to nearly 135 $\mathrm{kJ} \cdot \mathrm{mol}^{-1}$ at low conversion of $15 \%$ and subsequently drops to about $30 \mathrm{~kJ} \cdot \mathrm{mol}^{-1}$ at $90 \%$ conversion. For Coal S1.3, there is a steady graduate fall in activation energy from $115 \mathrm{~kJ} \cdot \mathrm{mol}^{-1}$ to $25 \mathrm{~kJ} \cdot \mathrm{mol}^{-1}$ at $90 \%$ conversion. Coal $\mathrm{S} 1.2$ shows a similar trend with high activation energy of $300 \mathrm{~kJ} \cdot \mathrm{mol}^{-1}$ at $10 \%$ conversion reducing down to $15 \mathrm{~kJ} \cdot \mathrm{mol}^{-1}$ for a $90 \%$ conversion. However, Raw HC sample does not follow the usual trend observed for the above samples. The activation energy curve crawls up from $70 \mathrm{~kJ} \cdot \mathrm{mol}^{-1}$ to $95 \mathrm{~kJ} \cdot \mathrm{mol}^{-1}$ for a $30 \%$ conversion and subsequently, in a very unusual bouncy manner, reduces down to $55 \mathrm{~kJ} \cdot \mathrm{mol}^{-1}$ at $90 \%$ conversion. The low initial activation energy value of Raw HC can be attributed to the cleaving of some weak bonds and elimination of volatile components from the coal macromolecule as the strong bonds are not cleaved at the beginning of the process.

Therefore, it is quite possible to notice a rise in the activation energy as the reaction proceeds because more energy is required to decompose the stable molecules. With the progress of decomposition process, the value of activation energy increased up to conversion of $30 \%$ with breaking of strong covalent linkages. For higher conversion values above $30 \%$ the activation energy gradually decreases intermittently, with slight increase at 50\% and $90 \%$ conversions. The common notion behind the gradual fall in activation energy with progress of conversion, is that during the decomposition process at high temperature with a high conversion value when most of the stable compounds are ruptured, less stable molecules which are easier to fragment are present, hence the less energy barrier to overcome for the decomposition reaction to continue. The arithmetic means of the activation energy was calculated by Friedman, Flynn Wall Ozawa and Kissinger-Akahira-Sunose iso-conversional methods and the results have been shown in Figure 13. The obtained values are noticeably closer to the average activation energy obtained from the Kissinger method, for each sample.

For coal S1.4, the initial activation energy is high due to the onset of chemical reactions that proceed slowly with copious evolution of volatile products. Owing to the coking nature of the coal samples, high activation energy is thought to be the result of destructive distillation reactions in the presence of limited amounts of air. The organic matter of the sample begins to decompose thermally as it arrives $600 \mathrm{~K}$ (Figure 14) to form and liberate mixtures of gas and liquid that can be considered as the coal plastic mass. Between temperatures $700 \mathrm{~K}$ to $820 \mathrm{~K}$ (DTG curve), the plastic mass evolved as coal gas and condensable vapors (vola- 
tiles) are combusted in the gas phase due to the presence of air. With the progress of thermal decomposition process from $35 \%$ conversion onwards, the value of activation energy keeps decreasing up to conversion of $85 \%$ after which it becomes steady. This behavior emphasizes that most of the stable molecules are cleaved from the coal matrix with the breaking of strong covalent linkages in the $10 \%$ to $35 \%$ conversion range of the sample. For higher conversion values above $35 \%$ the activation energy gradually decreases. The reason arises from the fact that during the decomposition process at high temperature beyond $825 \mathrm{~K}$, less stable molecules which are easier to break are present, so less energy barrier is required for decomposition at this step and the value of activation energy decreases with progress of conversion.

It is well known in literature that high temperature coal coking mechanism involves two stages of formation; the caking phase to produce a plastic mass and the shrinking phase. During this phase conversion, with further increase in temperature above $825 \mathrm{~K}$, the carbon laminae increase continuously [44] [45]. Coal S1.4 is composed of alkyl side chains, aliphatic or alicyclic structures and dicarboxylic acid groups, significantly much more compared to Coal S1.2; which is why the former gets combusted faster $\left(\right.$ rate $2^{\circ} \mathrm{C} / \mathrm{min}$ at $950^{\circ} \mathrm{C}$, rate $5^{\circ} \mathrm{C} / \mathrm{min}$ at $1200^{\circ} \mathrm{C}$ and rate $7^{\circ} \mathrm{C} / \mathrm{min}$ at $1375^{\circ} \mathrm{C}$ ). Quantifiably, a larger $\mathrm{DTG} \% / \mathrm{min}$ is also observed for Coal S1.4 over Coal S1.2.

\section{Conclusion}

In this study, the combustion kinetics of Jamadoba semi-bituminous coal was carried out by means of thermogravimetric analysis (TG) in the temperature range of $300 \mathrm{~K}-1700 \mathrm{~K}$ at three different heating rates of 2,5 and $7^{\circ} \mathrm{C} \cdot \mathrm{min}^{-1}$ under air atmosphere. In this work, kinetic study and thermal behavior of the studied coal samples were presented where Arrhenius parameters were determined and compared through four different model-free methods of Kissinger, Flynn Wall Ozawa, Kissinger-Akahira-Sunose and Friedman. Model-free (isoconversional) linear differential methods are free from any assumption of kinetic model and the order of reaction. Literature also says that the model-free methods show a better graphical fit; hence the accuracy of the results is better than the other differential and integral methods. However, model-free calculations are limited to the determination of activation energy only. Variation in activation energy observed with the extent of conversion has no theoretical meaning unless multiple steps occur in the reaction. The values of activation energy and other kinetic parameters that are consistent with all the non-isothermal data derived at several heating rates appear to vary with the selection of the model-free methods. The kinetic parameters obtained in this study can be useful for researchers to gain an insight into the combustion dynamics of Jamadoba coal and improve upon the optimization of the process conditions.

\section{Conflicts of Interest}

The authors declare no conflicts of interest regarding the publication of this paper. 


\section{References}

[1] Coal India (2011) India's Energy Scenario \& Coal. https://www.coalindia.in/en-us/company/aboutus.aspx

[2] Silva Filho, C.G.D. and Milioli, F.E. (2008) A Thermogravimetric Analysis of the Combustion of a Brazilian Mineral coal. Quimica Nova, 31, 98-100. https://doi.org/10.1590/S0100-40422008000100021

[3] Serageldin, M.A. and Pan, W.-P. (1973) Coal: Kinetic Analysis of Thermogravimetric Data. Thermochemica Acta, 71, 1-14. https://doi.org/10.1016/0040-6031(83)80350-5

[4] Wang, J.-H., Li, F., Chang, L.P. and Xie, K.-C. (2011) Combustion Characteristics and Kinetics of Lingwu Coal and Its Macerals. Energy Sources, 33, 529-538. https://doi.org/10.1080/15567030903097020

[5] Kim, S.-T., Scaroni, A.W. and Fatemi-Badi, M. (1988) Effect of Maceral Composition and Vitrinite Reflectance on the Combustion Behavior of Bituminous Coals. Fuel, 33, 4.

[6] Bryers, R.W. (1995) Investigation of the Reactivity of Macerals Using Thermal Analysis. Fuel Processing Technology, 44, 25-54. https://doi.org/10.1016/0378-3820(94)00119-E

[7] Borrego, A.G., Alvarez, D. and Menendez, R. (1997) Effects of Inertinite Content in Coal on Char Structure and Combustion. Energy Fuels, 11, 702-708. https://doi.org/10.1021/ef960130m

[8] Thomas, C.G., Gosnell, M.E., Gawronski, E., Phong-anant, D. and Shibaoka, M. (1993) The Behaviour of Inertinite Macerals under Pulverized Fuel Combustion Conditions. Organic Geochemistry, 20, 779-788. https://doi.org/10.1016/0146-6380(93)90062-G

[9] Choudhury, N., Sarkar, P., Mukherjee, A., Sahu, S.G., Boral, P. and Choudhury, A. (2006) Studies on the Combustion Behaviour of Blends of Indian Coals by TGA and Drop Tube Furnace. Fuel Processing Technology, 87, 191-199.

https://doi.org/10.1016/j.fuproc.2005.05.002

[10] Choudhurya, N., Biswas, S., Sarkara, P., Kumar, M., Ghosal, S., Mitra, T., Mukherjee, A. and Choudhurya, A. (2008) Influence of Rank and Macerals on the Burnout Behaviour of Pulverized Indian Coal. International Journal of Coal Geology, 74, 145-183. https://doi.org/10.1016/j.coal.2007.11.002

[11] Khawam, A. and Flanagan, D.R. (2006) Basics and Applications of Solid-State Kinetics: A Pharmaceutical Perspective. Journal of Pharmaceutical Sciences, 95, 472-498. https://doi.org/10.1002/jps.20559

[12] Smith, S.E., Neavel, R.C., Hippo, E.J. and Miller, R.N. (1981) DTG: A Combustion of Coals in the Exxon Coal Library. Fuel, 60, 458-462. https://doi.org/10.1016/0016-2361(81)90103-4

[13] Das, T.K. (2001) Thermogravimetric Characterization of Maceral Concentrates of Russian Coking Coals. Fuel, 80, 97-106. https://doi.org/10.1016/S0016-2361(00)00058-2

[14] Levenspiel, O. (1972) Chemical Reaction Engineering. John Willey \& Sons, Singapore.

[15] Hameed, Z., Naqvi, S.R., Naqvi, M., Ali, I., Taqvi, S.A.A., Gao, N., Hussain, S.A. and Hussain, S. (2020) A Comprehensive Review on Thermal Coconversion of Biomass, Sludge, Coal, and Their Blends Using Thermogravimetric Analysis. Journal of Chemistry, 2020, Article ID: 5024369. https://doi.org/10.1155/2020/5024369 
[16] Burnham, A.K. and Braun, R.L. (1999) Global Kinetic Analysis of Complex Materials. Energy Fuels, 13, 1-22. https://doi.org/10.1021/ef9800765

[17] Kissinger, H.E. (1956) Variation of Peak Temperature with Heating Rate in Differential Thermal Analysis. Journal of Research of the National Bureau of Standards, 57, 217-221. https://doi.org/10.6028/jres.057.026

[18] Kissinger, H.E. (1957) Reaction Kinetics in Differential Thermal Analysis. Analytical Chemistry, 29, 1702-1706. https://doi.org/10.1021/ac60131a045

[19] Ozawa, T.A. (1965) New Method of Analyzing Thermogravimetric Data. Bulletin of the Chemical Society of Japan, 38, 1881-1886. https://doi.org/10.1246/bcsj.38.1881

[20] Ozawa, T. (1970) Kinetic Analysis of Derivate Curves in Thermal Analysis. Journal of Thermal Analysis, 2, 301-324. https://doi.org/10.1007/BF01911411

[21] Heireche, L. and Belhadji, M. (2007) The Methods Matusita, Kissinger and Ozawa in the Study of the Crystallization of Glasses. The Case of Ge-Sb-Te Alloys. Chalcogenide Letters, 4, 23-33.

[22] Prasad, T.P., Kanungo, S.B. and Ray, H.S. (1992) Non-Isothermal Kinetics: Some Merits and Limitations. Thermochimica Acta, 203, 503-514. https://doi.org/10.1016/0040-6031(92)85220-P

[23] Everson, R.C., Neomagus, H.W.J.P., Kasaini, H. and Njapha, D. (2006) Reaction Kinetics of Pulverized Coal-Chars Derived from Inertinite-Rich Coal Discards: Gasification with Carbon Dioxide and Steam. Fuel, 85, 1076-1082. https://doi.org/10.1016/j.fuel.2005.10.016

[24] Scaccia, S. (2013) TG-FTIR and Kinetics of Devolatilization of Sulcis Coal. Journal of Analytical and Applied Pyrolysis, 104, 95-102. https://doi.org/10.1016/j.jaap.2013.09.002

[25] Idris, S.S., Rahman, N.A., Ismail, K., Alias, A.B., Rashid, Z.A. and Aris, M.J. (2010) Investigation on Thermochemical Behaviour of Low Rank Malaysian Coal, Oil Palm Biomass and Their Blends during Pyrolysis via Thermogravimetric Analysis (TGA). Bioresource Technology, 101, 4584-4592. https://doi.org/10.1016/j.biortech.2010.01.059

[26] Jiang, G., Nowakowski, D.J. and Bridgwater, A.V. (2010) A Systematic Study of the Kinetics of Lignin Pyrolysis. Thermochimica Acta, 498, 61-66. https://doi.org/10.1016/j.tca.2009.10.003

[27] Sbirrazzuoli, N., Vincent, L., Mija, A. and Guigo, N. (2009) Integral, Differential and Advanced Isoconversional Methods: Complex Mechanisms and Isothermal Predicted Conversion-Time Curves. Chemometrics and Intelligent Laboratory Systems, 96, 219-226. https://doi.org/10.1016/j.chemolab.2009.02.002

[28] Mianowski, A. and Radko, T. (1993) Isokinetic Effect in Coal Pyrolysis. Fuel, 72, 1537-1539. https://doi.org/10.1016/0016-2361(93)90012-Q

[29] Arenillas, A., Rubiera, F., Pevida, C. and Pis, J.J. (2001) A Comparison of Different Methods for Predicting Coal Devolatilisation Kinetics. Journal of Analytical and Applied Pyrolysis, 58-59, 685-701. https://doi.org/10.1016/S0165-2370(00)00183-2

[30] Vyazovkin, S. (2000) Computational Aspects of Kinetic Analysis: Part C. The ICTAC Kinetics Project-The Light at the End of the Tunnel? Thermochimica Acta, 355, 155-163. https://doi.org/10.1016/S0040-6031(00)00445-7

[31] Starink, M.J. (1997) On the Applicability of Isoconversion Methods for Obtaining the Activation Energy of Reactions within a Temperature-Dependent Equilibrium Stat. Journal of Materials Science, 32, 6505-6512. https://doi.org/10.1023/A:1018655026036 
[32] Simon, P. (2004) Isoconversional Methods-Fundamentals, Meaning and Application. Journal of Thermal Analysis and Calorimetry, 76, 123-132. https://doi.org/10.1023/B:JTAN.0000027811.80036.6c

[33] Khawam, A. and Flanagan, D.R. (2005) Complementary Use of Model-Free and Modelistic Methods in the Analysis of Solid-State Kinetics. Journal of Physical Chemistry $B, 109,10073-10080$. https://doi.org/10.1021/jp050589u

[34] Khawam, A. (2007) Application of Solid-State Kinetics to Desolvation Reactions. Ph.D. Thesis, University of Iowa, Iowa City.

[35] Heydari, M., Rahman, M. and Gupta, R. (2015) Kinetic Study and Thermal Decomposition Behavior of Lignite Coal. International Journal of Chemical Engineering, 2015, Article ID: 481739. https://doi.org/10.1155/2015/481739

[36] Akahira, T. and Sunose, T. (1969) Transactions of Joint Convention of Four Electrical Institutes. 246.

[37] Mittemeijer, E.J. (1992) Analysis of the Kinetics of Phase Transformations. Journal of Materials Science, 27, 3977-3987. https://doi.org/10.1007/BF01105093

[38] Ozawa, T. (1970) Kinetic Analysis of Derivative Curves in Thermal Analysis. Journal of Thermal Analysis and Calorimetry, 2, 301-324. https://doi.org/10.1007/BF01911411

[39] Starink, M.J. (2003) The Determination of Activation Energy from Linear Heating Rate Experiments: A Comparison of the Accuracy of Isoconversion Methods. Thermochimica Acta, 404, 163-176. https://doi.org/10.1016/S0040-6031(03)00144-8

[40] Haykiri-Acma, H. and Yaman, S. (2008) Effect of Co-Combustion on the Burnout of Lignite/Biomass Blends: A Turkish Case Study. Waste Management, 28, 2077-2084. https://doi.org/10.1016/j.wasman.2007.08.028

[41] Guldogan, Y., Durusoy, T. and Bozdemir, T. (2002) Effects of Heating Rate and Particle Size on Pyrolysis Kinetics of Gediz Lignite. Energy Sources, 24, 753-760. https://doi.org/10.1080/00908310290086671

[42] Gunes, M. and Gunes, S.K. (2008) Distributed Activation Energy Model Parameters of Some Turkish Coals. Energy Sources, Part A: Recovery, Utilization and Environmental Effects, 30, 1460-1472. https://doi.org/10.1080/15567030701258501

[43] Speight, J.G. (2012) Mineral Matter: The Chemistry and Technology of Coal. 3rd Edition, Taylor \& Francis, Abingdon-on-Thames, 193-211.

[44] Vyazovkin, S. (2000) Kinetic Concepts of Thermally Stimulated Reactions in Solids: A View from a Historical Perspective. International Reviews in Physical Chemistry, 19, 45-60. https://doi.org/10.1080/014423500229855

[45] Zhang, D.X. (2009) Coal Technology 2. In: Gao, J.S., Ed., Coal, Oil Shale, Natural Bitumen, Heavy Oil and Peat, EOLSS Publishers Company Limited, Paris, Vol. 1, $1-39$. 